\title{
Where You Are, Not What You See: \\ The Impact of Learning Environment on Mind Wandering and Material Retention
}

\author{
Trish L. Varao-Sousa \\ University of British Columbia \\ Department of Psychology \\ Vancouver, Canada \\ tvaraosousa@psych.ubc.ca
}

\author{
Caitlin Mills \\ University of New Hampshire \\ Department of Psychology \\ Durham, USA \\ caitlin.mills@unh.edu
}

\author{
Alan Kingstone \\ University of British Columbia \\ Department of Psychology \\ Vancouver, Canada \\ alan.kingstone@ubc.ca
}

\begin{abstract}
Online lectures are an increasingly popular tool for learning, yet research on instructor visibility during an online lecture, and students' environmental settings, has not been well-explored. The current study addresses this gap in the literature by experimentally manipulating online display format and social learning settings to understand their influence on student learning and mind-wandering experiences. Results suggest that instructor visibility within an online lecture does not impact students' MW or retention performance. However, we found some evidence that students' social setting during viewing has an impact on MW $(p=.05)$. Specifically, students who watched the lecture in a classroom with others reported significantly more MW than students who watched the lecture alone. Finally, social setting also moderated the negative relationship between MW and material retention. Our results demonstrate that learning experiences during online lectures can vary based on where, and with whom, the lectures are watched.
\end{abstract}

\section{CCS CONCEPTS}

\section{- Applied computing E-learning • Applied}

computing $\sim$ Computer-managed instruction

\section{KEYWORDS}

Online lectures, learning setting, mind-wandering, memory

\begin{abstract}
Permission to make digital or hard copies of part or all of this work for personal or classroom use is granted without fee provided that copies are not made or distributed for profit or commercial advantage and that copies bear this notice and the full citation on the first page. Copyrights for third-party components of this work by others than ACM must be honored. To copy otherwise, or republish, to post on servers or to redistribute to lists, requires prior specific permission and/or a fee. Request permissions from Permissions@acm.org.
\end{abstract}

LAK'19, March 4-8, 2019, Tempe, AZ, USA

(C) 2019 Copyright held by the owner/author(s).

ACM ISBN 978-1-4503-6256-6/19/03 ..\$15.00

https://doi.org/10.1145/3303772.3303824

\section{INTRODUCTION}

The past decade has witnessed online learning environments become a staple in both university settings and in recreational forums (e.g., edX, Coursera, etc.). In the United States and Canada, more than $22 \%$ of college students report taking at least one online course [2]. Although significant efforts have been devoted to modelling and understanding student engagement and learning during such online courses [10], there is relatively little experimental work exploring how learning and engagement are affected by the way the online lectures are presented or where the student watches the lectures. This gap in the literature is particularly concerning given that mind-wandering (MW) is affected by precisely these factors, and MW is pervasive in educational settings [22]. MW is defined here as a shift in attentional focus from the primary task to an unrelated stream of thought [20].

MW occurs very frequently during online learning: up to 20 $30 \%$ of the time while reading material online $[18,26]$ or learning from an online tutoring system [9], and up to $40 \%$ of the time during online lectures [22]. Critically, negative correlations between MW rates and comprehension scores are often reported in educational settings [14, 22] (but see also [27]). The prevalence of MW, combined with its frequent negative relationship with comprehension, highlights the importance of understanding how features of online learning influence MW. The current study addresses two potentially critical features: 1) the importance of being able to see the instructor during an online lecture and 2) the social setting within which the lecture is viewed.

\subsection{Related Work}

Online lectures provide an opportunity to easily change and compare features of a learning environment. By making small changes to the display or content, researchers can gain a better understanding of what keeps students engaged. Indeed, student engagement in online lectures is an understudied but critical factor, given the high rates of online lecture drop out [11] and increasing MW rates over long intervals [21]. The high drop-out rates, however, do not necessarily outweigh the benefits of reaching more learners with distance education and the ability to retain 
valuable learning analytics information that can be used to improve learning over time.

Previous work on the effectiveness of pre-recorded lectures has yielded inconsistent results with respect to their effectiveness compared to live lectures [4]. For example, Sankaran and Bui [17] found that the use of deep or surface learning strategies did not differentially influence motivation or performance between web and live lecture settings. In contrast, McKinney et al. [15] found that students who listened to a lecture recording via podcast performed better on an exam than those who attended a live lecture. More recently, Varao-Sousa and Kingstone [25] found that material retention was worse in pre-recorded lectures versus live lectures, but MW rates were not impacted. Given the inconsistent findings with regard to the effectiveness of pre-recorded video lectures, it is plausible that features either within the video lectures or within the student's environment may be impacting engagement and effectiveness. Such features are the focus of the current study. We review the relevant work below.

1.1.1 Features of the lecture. A few studies have capitalized on the idea that features of the lecture may impact the learning experience by manipulating specific features in online lectures, such as length of lecture content, and video display content [12, 28]. One feature of online learning that is often inconsistent in online learning displays is whether an instructor is actually visible. The idea that instructor visibility may influence attention is well motivated by studies indicating that socially-relevant or sociallyrelated information (i.e., faces) captures our attention [13, 23]. Thus, the visibility of an instructor could impact the way that students actively attend to material (for example, by modulating MW reports).

Chen and $\mathrm{Wu}$ [5] tested this idea by manipulating lecture format, with students watching the lecture in one of three possible ways: a pre-recorded version of a lecture, a visual of lecture slides with the instructor voicing over the content, or a visual of lecture slides with a video of the instructor inset on the screen. Their results indicated that sustained attention was better in the voiceover compared to the instructor overlay format, yet learning performance was the worst in the voice-over condition compared to the other two. However, it is difficult to know how well these results will generalize at scale since sustained attention was inferred via a single-electrode EEG system. A more recent investigation manipulated lecture presentation using three conditions: audio-only, audio with text, and audio with instructor visible [28]. MW was measured via thought probes during viewing. In this study, neither MW nor comprehension were affected by changes in content display.

The mixed results found across these two studies, with respect to the impact of instructor visibility on attentional processes, may stem from the different stimulus manipulations and MW measurements. In the present study, we sought to provide a specific manipulation by only varying the instructor's visibility in the video frame, and to test for its effect on MW and material retention.
1.1.2 Features of the environment. Aside from visibility of the instructor, the learning setting of online material can be highly variable. As noted above, cues related to social relevance can influence attention capture, and online lecture watching can differ in terms of social presence. For example, students may view content alone in their own space, in a shared setting (e.g., library), or as part of a satellite course with other students. Thus, the mere presence of others or the solitary nature of a setting could influence student attention to material, and by extension, material retention.

Abdous and Yoshimura [1] examined if final grades were influenced by whether a course was taken in a live class, through a video broadcasting site, or via live video-streaming. Their results suggested that setting did not impact grade or course satisfaction. However, this study did not involve any pre-recorded lectures - all participants watched the lecture in real-time. Given that many students in online courses watch pre-recorded videos in a multitude of settings, the current study sought to address if social setting mattered while viewing pre-recorded videos.

We also extend previous work by examining shared spaces as a social setting for online learning. This setting differs from work examining differences between live and online lecture formats [4, $15,17,25]$, as students are often in group settings without a shared, scheduled event (e.g., on campus, libraries, coffee shops).

\subsection{Current Study}

There is great diversity in online lecture presentation as well as learners' environments. We therefore experimentally manipulated two features that often vary when taking an online course: 1) the presentation of the lecture (instructor visibility) and 2) the learning setting (the presence, or lack, of others).

We address the following research questions: Research Question 1. What are the main effects of presentation and setting on MW, and on comprehension? Research Question 2. What is the relationship between MW and comprehension, and does social setting or instructor visibility moderate this relationship?

\section{METHODS}

\subsection{Participants}

Two hundred and seventy-nine undergraduate student participants $\left(M_{\text {age }}=20\right.$ years, $S D_{\text {age }}=2.1$ years, 198 women and $\left.81 \mathrm{men}\right)$ were recruited from the University of British Columbia and participated for course credit. Ethics approval was obtained from UBC's Behavioural Research Ethics Board. Written, informed consent was obtained from each student at the start of the study.

\subsection{Design}

A $3 \times 2$ between-subjects design was employed. Social setting was manipulated in three ways, with students completing the study either: alone in a laboratory testing room (Alone), in a classroom with other students collectively viewing a single projector screen (Group - shared screen), or in group with other students but each student viewed the lecture on their own computer monitor (Group - individual screens). The visibility of the instructor was manipulated in two ways: either the instructor was fully visible in 
the video recording (Instructor Present), or the instructor was cropped out of the video recording (Instructor Absent).

\subsection{Materials and Measures}

2.3.1 Lecture Materials. A 58 minute video recorded lecture on Psychotherapy was used for all groups (adapted from [25]). For the instructor-absent condition the video display was cropped so that only the lecture slides (and not the instructor) were visible.

2.3.2 Mind-Wandering Probes. Across the lecture six MW probes were displayed visually on the lecture slides at the following time points: 4:30, 13:45, 20:02, 31:52, 44:27, and 57:20 minutes. These probes were already within the lecture content used, and originally selected to appear following every 3-4 slides. The probes asked: "In the moment prior to this slide, were you mind wandering?" and students responded by circling "Yes" or "No" on the response sheet provided. Students had an average of 30 seconds to record their responses before the video continued.

2.3.3 Retention Test. A six-item True-False test based on the lecture content was administered via slideshow at the end of the lecture. Students recorded their responses on the participant response sheet.

2.3.4 Other Measures. We also counted the number of note pages students made during the lecture and assessed interested and motivation using single questions. A 5-point Likert Scale was used, where $1=$ Low Interest/Motivation and $5=$ High Interest/Motivation. There were no differences across conditions, thus alleviating any concerns of confounding effects of notes, interest, or motivation between conditions. We do not discuss these measures further given the scope of the paper.

\subsection{Procedure}

An online booking system was used to recruit students for the experiment. For each of the three experimental conditions, a research assistant explained the nature of the study to the students, and provided separate informed consent, response sheets and lined paper. The following definition of MW was provided: "Any thought that is not related to the lecture material being presented" and examples were provided (e.g., thoughts relating to getting lunch later, thinking about something that happened on the weekend, etc.). Students were asked to respond on the participant sheet, and told that they were free to make notes during the video as they would during an actual class. Students were also informed that they would complete a short comprehension test at the end of the session, during which time they would not have access to their notes. Students in the group-individual screens condition wore headphones while viewing the lecture. The video was started by the researcher, and then the researcher exited the room, leaving the student(s) alone to view the lecture. At the end of the video, the student/s submitted any notes that were taken to the researcher and then completed the retention test, as well as indicating their interest and motivation for the material in the video.

\section{RESULTS}

Table 1 presents the descriptive statistics for the variables measured across each level of design. We discuss the results for each of our research questions below. Analyses were completed using the lme4 package in R [3], and significance testing was completed using the 'car' package [7].

\subsection{What are the impacts of instructor visibility and social setting?}

Logistic mixed effects regressions were computed to assess the main effects of instructor visibility/absence and social setting on MW and material retention. Models predicting MW responses were constructed by regressing the binary probe responses (1 indicating the student was off-task and 0 indicating the student was on task) on instructor visibility (categorical fixed effect with two levels) and social setting (categorical fixed effect with three levels), as well as their interaction term. Since every student responded to multiple probes, student ID was included as a random effect to remove the within-subject variance introduced by the repeated measures design. Models for retention were constructed using the same fixed and random effect structure. The dependent variable was correctness $(1=$ correct vs. $0=$ incorrect $)$ on the test questions.

3.1.1 Mind wandering. We found no evidence for a main effect of instructor visibility on MW $(p=.49)$ and no interaction between instructor visibility and social setting $(p=.58)$. However, we did find evidence for an effect of social setting on MW, $\chi 2(2)$ $=5.90, p=.05$. Post-hoc comparisons of social group indicate that students who watched in the group - shared screen condition reported MW significantly more than students who watched the lecture alone in the laboratory, $B=.38, S E=.16, p=.02$. In contrast, MW reports did not differ between the group-individual screens and the other two conditions (group-shared screen and alone), respectively, $p \mathrm{~s}>.10$.

3.1.2 Retention Test. We found no significant main effects and no interaction between instructor visibility and social setting on retention, $p \mathrm{~s}>.10$. Thus, all students performed similarly well,

Table 1. Raw unstandardized descriptives.

\begin{tabular}{|c|c|c|c|c|c|c|}
\hline & \multicolumn{3}{|c|}{$\begin{array}{c}\text { Instructor Present } \\
\mathrm{M}(\mathrm{SD})\end{array}$} & \multicolumn{3}{|c|}{$\begin{array}{c}\text { Instructor Absent } \\
\text { M (SD) }\end{array}$} \\
\hline & Alone & $\begin{array}{l}\text { Group - Shared } \\
\text { Screen }\end{array}$ & $\begin{array}{l}\text { Group - Individual } \\
\text { Screens }\end{array}$ & Alone & $\begin{array}{l}\text { Group - Shared } \\
\text { Screen }\end{array}$ & $\begin{array}{c}\text { Group - Individual } \\
\text { Screens }\end{array}$ \\
\hline $\begin{array}{l}\text { Main Measures } \\
\text { Prop. MW [0-1] }\end{array}$ & $.45(.22)$ & $.57(.25)$ & $.50(.25)$ & $.47(.22)$ & $.52(.27)$ & $.48(.29)$ \\
\hline Retention [0-1] & $.80(.15)$ & $.76(.21)$ & $.74(.19)$ & $.82(.17)$ & $.77(.22)$ & $.80(.21)$ \\
\hline
\end{tabular}


regardless of what version of the lecture they saw or in which setting they watched the video.

\subsection{What is the relationship between mind-wandering and retention?}

We next examined the relationship between MW and retention, and whether the instructor visibility or social setting moderated this relationship. First, we regressed average retention scores on average MW separately to assess the overall relationship. As expected, retention was significantly, and negatively related to MW, $B=-.14, S E=.04, p=.003$.

We also tested if social setting or instructor visibility moderated the relationship between MW and retention - i.e., is it possible that MW shared a more negative association with retention in certain conditions? We tested this by computing two-way interactions: 1) $\mathrm{MW} \times$ social setting and 2$) \mathrm{MW} \times$ presentation style. $^{1}$

We found no evidence that instructor visibility moderated the relationship between MW and retention. However, there was a significant two-way interaction between MW and social setting, $F(2)=3.22, p=.04$. MW had a stronger negative relationship with retention for students in the group-individual screens condition, $B$ $=-.27, S E=.07, p<.001$, compared to group-shared screen $(B=-$ $.02, S E=.08, p=.83)$ or alone conditions $(B=-.08, S E=.08, p=$ $.34)$.

\section{DISCUSSION AND CONCLUSION}

The present study investigated whether MW and/or retention would be influenced by instructor visibility or social setting. The results indicate that instructor visibility does not impact MW or retention, but there is evidence to suggest that social setting may influence MW rates. MW was higher in the group - shared screen condition compared to watching the lecture alone. We also replicated previous studies suggesting that MW and retention are negatively related $[6,19,26]$, and extend these findings by showing that certain social conditions may amplify this effect. In particular, this negative relationship was the strongest when students were in a group setting but viewing the lecture on their own individual screens.

Future lines of work could be developed to determine why group setting has an impact on MW rates. Research suggests that the ability to see a peer's gaze direction or activity during learning can influence one's own attention [16]. Although there was no collected evidence in the present study that students in the group-shared screen condition had more peer distractions, prior work does suggest that individuals' attention is strongly biased to, and by, the presence of others $[13,23]$. Determining the specific ways in which the presence of others influences student success would benefit research related to promoting inclusion in online courses. Future work could also examine why there was a negative correlation between MW and retention in the group-individual screens condition, particularly since this condition did not display the highest overall rates of MW.

\footnotetext{
${ }^{1} \mathrm{We}$ did not have enough power to test for a three-way interaction (requiring roughly four-fold the sample size needed for a two-way interaction [8]).

One possibility is that participants experienced different types of inattention that were more harmful to learning, such as distractiona distinct form of inattention [24]. For example, students may have been distracted by the mere presence of their peers and the inability to monitor what others were doing. As the present study only measured rates of $\mathrm{MW}$, it is possible that distractions may have also influenced the underlying relationships found. A better understanding of factors that influence learners' cognitive states during online settings will clearly be valuable to predictive models of in attention and learning.

This study is not without limitations. First, despite testing nearly 300 students some of our effects may have been underpowered for detecting small effect sizes: For example, a sample size of over 320 is recommended to detect a 'small' interaction effect $(d=.20)$ with a power of .90 . Second, although we attempted to mimic three ecological settings in which students watch online lectures, devising ways to truly capture students in their naturalistic settings can only enhance the external validity of the findings.

The steady increase of students partaking in online learning material is contrasted with a lack of understanding about optimal features of the lecture and one's own environment. We provide some insight to this issue and suggest that future work may benefit from considering more contextual features such as social setting. Specifically, knowing where a student is while viewing the lecture may inform predictive models of student attention and engagement.

\section{ACKNOWLEDGMENTS}

This work was partially supported by a Canadian Graduate Scholarship from the National Science and Engineering Research Council (NSERC) of Canada. This research was also supported by an NSERC Discovery grant, and a Social Sciences and Humanities Research Council (SSHRC) grant. Any opinions, findings and conclusions, or recommendations expressed in this paper are those of the authors and do not necessarily reflect the views of NSERC and SSHRC. We also thank Faith Jabs for her help with the data collection.

\section{REFERENCES}

[1] Abdous, M. and Yoshimura, M. 2010. Learner outcomes and satisfaction: A comparison of live video-streamed instruction, satellite broadcast instruction, and face-toface instruction. Computers \& Education. 55, 2 (Sep. 2010), $733-741$ DOI:https://doi.org/10.1016/j.compedu.2010.03.006.

[2] Allen, I.E. and Seaman, J. 2009. Learning on Demand: Online Education in the United States, 2009. Sloan Consortium (NJ1). (Dec. 2009).

[3] Bates, D. 2004. Sparse matrix representations of linear mixed models. (2004).

[4] Bernard, R.M., Abrami, P.C., Lou, Y., Borokhovski, E., Wade, A., Wozney, L., Wallet, P.A., Fiset, M. and Huang, B. 2004. How Does Distance Education Compare With 
Classroom Instruction? A Meta-Analysis of the Empirical Literature. Review of Educational Research. 74, 3 (Sep. 2004), 379-439. DOI:https://doi.org/10.3102/00346543074003379.

[5] Chen, C.-M. and Wu, C.-H. 2015. Effects of different video lecture types on sustained attention, emotion, cognitive load, and learning performance. Computers \& Education. 80, (Jan. 2015), 108-121. DOI:https://doi.org/10.1016/J.COMPEDU.2014.08.015.

[6] Dixon, P. and Li, H. 2013. Mind wandering in text comprehension under dual-task conditions. Frontiers in Psychology. 4, OCT (2013), 1-14. DOI:https://doi.org/10.3389/fpsyg.2013.00682.

[7] Fox, J., Friendly, M. and Weisberg, S. 2013. Hypothesis tests for multivariate linear models using the car package. The R Journal. 5.1, (2013), 39-52.

[8] Heo, M. and Leon, A.C. 2010. Sample Sizes Required to Detect Two-Way and Three-Way Interactions Involving Slope Differences in Mixed-Effects Linear Models. Journal of Biopharmaceutical Statistics. 20, 4 (May 2010), $\quad$ 787-802. DOI:https://doi.org/10.1080/10543401003618819.

[9] Hutt, S., Mills, C., White, S., Donnelly, P.J. and D 'Mello, S.K. 2016. The Eyes Have It: Gaze-based Detection of Mind Wandering during Learning with an Intelligent Tutoring System. Proceedings of the 9th International Conference on Educational Data Mining. (2016), 86-93.

[10] Joksimović, S., Poquet, O., Kovanović, V., Dowell, N., Mills, C., Gašević, D., Dawson, S., Graesser, A.C. and Brooks, C. 2018. How Do We Model Learning at Scale? A Systematic Review of Research on MOOCs. Review of Educational Research. 88, 1 (Feb. 2018), 43-86. DOI:https://doi.org/10.3102/0034654317740335.

[11] Kim, J., Guo, P.J., Seaton, D.T., Mitros, P., Gajos, K.Z. and Miller, R.C. 2014. Understanding in-video dropouts and interaction peaks inonline lecture videos. Proceedings of the first ACM conference on Learning @ scale conference - L@S'14 (2014),31-40.

[12] Kizilcec, R., Papadopoulos, K. and Sritanyaratana, L. 2014. Showing face in video instruction: effects on information retention, visual attention, and affect. Proceedings of the SIGCHI conference on human factors in computing systems. (2014).

[13] Langton, S., Watt, R. and Bruce, I. 2000. Do the eyes have it? Cues to the direction of social attention. Trends in cognitive sciences. 4, 2 (2000), 50-59.

[14] Lindquist, S.I. and McLean, J.P. 2011. Daydreaming and its correlates in an educational environment. Learning and Individual Differences. 21, 2 (Apr. 2011), 158-167. DOI:https://doi.org/10.1016/j.lindif.2010.12.006.

[15] McKinney, D., Dyck, J.L. and Luber, E.S. 2009. iTunes University and the classroom: Can podcasts replace Professors? Computers \& Education. 52, 3 (Apr. 2009), 617-623.

DOI:https://doi.org/10.1016/j.compedu.2008.11.004.

[16] Phillips, N.E., Ralph, B.C.W., Carriere, J.S.A. and Smilek, D. 2016. Examining the influence of saliency of peerinduced distractions on direction of gaze and lecture recall. Computers and Education. 99, (2016), 81-93.
DOI:https://doi.org/10.1016/j.compedu.2016.04.006.

[17] Sankaran, S.R. and Bui, T. 2001. Impact of Learning Strategies and Motivation on Performance: A Study in Web-Based Instruction. Journal of Instructional Psychology. 28, 3 (Sep. 2001), 191.

[18] Smallwood, J. 2011. Mind-wandering While Reading: Attentional Decoupling, Mindless Reading and the Cascade Model of Inattention. Language and Linguistics Compass. 5, 2 (Feb. 2011), 63-77. DOI:https://doi.org/10.1111/j.1749-818X.2010.00263.x.

[19] Smallwood, J., McSpadden, M. and Schooler, J.W. 2007. The lights are on but no one's home: meta-awareness and the decoupling of attention when the mind wanders. Psychonomic bulletin \& review. 14, 3 (Jun. 2007), 527533. DOI:https://doi.org/10.3758/BF03194102.

[20] Smallwood, J. and Schooler, J.W. 2006. The restless mind. Psychological bulletin. 132, 6 (Nov. 2006), 946-958. DOI:https://doi.org/10.1037/0033-2909.132.6.946.

[21] Szpunar, K.K., Khan, N.Y. and Schacter, D.L. 2013. Interpolated memory tests reduce mind wandering and improve learning of online lectures. Proceedings of the national academy of sciences of the united states of america. 110, 16 (Apr. 2013), 6313-6317. DOI:https://doi.org/10.1073/pnas.1221764110.

[22] Szpunar, K.K., Moulton, S.T. and Schacter, D.L. 2013. Mind wandering and education: from the classroom to online learning. Frontiers in Psychology. 4, August (Aug. 2013), 495.

DOI:https://doi.org/10.3389/fpsyg.2013.00495.

[23] Theeuwes, J. and Van der Stigchel, S. 2006. Faces capture attention: Evidence from inhibition of return. Visual Cognition. 13, 6 (Apr. 2006), 657-665. DOI:https://doi.org/10.1080/13506280500410949.

[24] Unsworth, N. and McMillan, B.D. 2014. Similarities and differences between mind-wandering and external distraction: A latent variable analysis of lapses of attention and their relation to cognitive abilities. Acta psychologica. 150, (2014), 14-25. DOI:https://doi.org/10.1016/j.actpsy.2014.04.001.

[25] Varao-Sousa, T.L. and Kingstone, A. 2015. Memory for lectures: How lecture format impacts the learning experience. PLoS ONE. 10, $11 \quad$ (2015). DOI:https://doi.org/10.1371/journal.pone.0141587.

[26] Varao Sousa, T.L., Carriere, J.S.A. and Smilek, D. 2013. The way we encounter reading material influences how frequently we mind wander. Frontiers in psychology. 4, (Jan. 2013), 892 DOI:https://doi.org/10.3389/fpsyg.2013.00892.

[27] Wammes, J.D. and Smilek, D. 2017. Examining the Influence of Lecture Format on Degree of Mind Wandering. Journal of Applied Research in Memory and Cognition. 6, 2 (Jun. 2017), 174-184. DOI:https://doi.org/10.1016/j.jarmac.2017.01.015.

[28] Wilson, K.E., Martinez, M., Mills, C., D’Mello, S., Smilek, D. and Risko, E.F. 2018. Instructor presence effect: Liking does not always lead to learning. Computers \& Education. 122, (Jul. 2018), 205-220. DOI:https://doi.org/10.1016/J.COMPEDU.2018.03.011. 